\title{
EFFECT OF ACUTE LYMPHOBLASTIC LEUKEMIA ON SALIVARY ALTERATIONS IN CHILDREN BEFORE AND AFTER CHEMOTHERAPY INDUCTION
}

\author{
Ghada A. ElBaz* and Rana A. Shalaby**
}

\begin{abstract}
Background: Approximately 2,56,000 children and young adults around the world developed acute lymphoblastic leukemia (ALL) which is the most common subtype of Leukemia. The aim of our study was to investigate the effect of acute lymphoblastic leukemia on salivary alterations in children before and after chemotherapy induction.

Materials and methods: This study included 45 children aged from 5 to 9 years. The sample was divided into 3 groups: Group A (control group); clinically healthy un-medicated children, Group $\mathrm{B}$ : children with a previous diagnosis of ALL and did not initiate the chemotherapy treatment and Group C: hospitalized children with a previous diagnosis of ALL and who were on chemotherapy (6 months- 1.5 years of treatment). From the selected children, stimulated whole saliva samples were collected in graduated tubes with funnels over a 5 minute period in the morning. Saliva samples were used to determine the stimulated salivary flow rate, salivary $\mathrm{pH}$, salivary total proteins and salivary alpha amylase.
\end{abstract}

Results: The results showed a significant reduction in the mean of salivary flow rate values between (group A) and (group C), also the difference was significant between (group B) and (group C). Regarding mean $\mathrm{pH}$ value, there was a significant difference between the 3 groups with an obvious reduction in $\mathrm{pH}$ values of groups B \& C. Moreover, the findings showed that the means of salivary total proteins and salivary alpha amylase were significantly higher in group B than in group A and group C.

Conclusion: According to ROC curve analysis salivary total proteins reflect an excellent predictor test where the value of total salivary proteins above $8.381 \mathrm{~g} / \mathrm{dl}$ indicated ALL leukemia with $100 \%$ accuracy in children.

KEYWORDS: Leukemia - chemotherapy - children- saliva.

\footnotetext{
* Associate Professor of Pediatric and Preventive Dentistry and Dental Public Health, Faculty of Dentistry, Suez Canal University.
}

**Assistant Lecturer of Pediatric Dentistry and Dental Public Health, Faculty of Dentistry, Fayoum University. 


\section{INTRODUCTION}

Children rarely develop cancer, but leukemia is the most common childhood cancer worldwide, it constitutes approximately $30 \%$ of all childhood cancers. Leukemia is a fatal disease in which there is an excessive proliferation and uncontrolled dissemination of many immature and abnormal types of white blood cells (WBCs) in the human bone marrow. The normal marrow elements are replaced by the poorly formed blast cells which eventually accumulate in human blood and various other tissues of the body ${ }^{1,2}$. The main subtypes of leukemia are lymphoblastic leukemia and myelogenous leukemia, both may be acute or chronic. Approximately 2,56,000 children and young adults around the world developed acute lymphoblastic leukemia (ALL) which is the most common subtype of Leukemia. It is treated with chemotherapy and/or radiation and survival rate is about $85 \%$ in children and $50 \%$ in adults. Both the disease and its treatment radically change the oral environment, leukemic children suffer from many oral health problems which include mucositis, trismus, xerostomia, gingival bleeding, ulcerations, taste alteration, skin desquamation, and opportunistic infections which further interfere inducing malnutrition ${ }^{4}$. In recent years, the saliva has been more and more often used to investigate many systemic diseases. Due to the simplicity of collection, low cost and non-invasive character of the method to obtain material for study, saliva tests have become a good method to diagnose various diseases as they enable the evaluation of the effects of treatment ${ }^{5-6}$. Time of diagnosis of leukemia is very important since in cases of early diagnosis, patients will have a survival rate as high as $80 \%$. By paying attention to the oral and salivary changes of leukemia, dentists can play an important role in its early diagnosis ${ }^{7}$. The present research was proposed to investigate the effect of acute lymphoblastic leukemia on salivary alterations in children before and after chemotherapy induction.

\section{MATERIALS AND METHODS}

The cross-sectional study included 45 children, of both sexes, aged from 5 to 9 years. The sample was divided into 3 groups: Group A control group: consisted of 15 clinically healthy un-medicated children require dental treatment selected from the Pediatric Dentistry Clinic, Faculty of Dentistry, Suez Canal University, Ismailia city, Egypt. Group B: consisted of 15 children with a previous diagnosis of ALL (standard-risk) and did not initiate the chemotherapy treatment. Group C: consisted of 15 hospitalized children with a previous diagnosis of ALL and who were on chemotherapy (6 months- 1.5 years of treatment). Thirty leukemic children (group B \& C) were selected from Children's Hospital, Faculty of Medicine, Zagazig University, Zagazig city, Egypt. The past and present medical history were recorded for each child to make sure that all children did not suffer from any systemic diseases and were not on any medication (except group B\&C) which might affect the variables under study. All parents of the selected children should sign an informed consent after explanation of the aim of the study and before any procedure. From the selected children, stimulated whole saliva samples were collected in graduate tubes with funnels over a 5 minute period $^{8}$ in the morning with the patient have not eaten or exercised any oral hygiene 90 minutes before the procedure. Saliva production was stimulated by chewing a sugar-free gum for 1 minute to determine the stimulated salivary flow rate, salivary $\mathrm{pH}$, salivary total proteins and salivary alpha amylase. The stimulated salivary flow rate was determined by the volume of saliva secreted per minutes ( $\mathrm{ml} / \mathrm{min})$. Salivary $\mathrm{pH}$ was also determined using AD $1030 \mathrm{pH}$ meter. Salivary total proteins 9 and salivary alpha amylase ${ }^{10}$ were estimated colorimetrically by using Bio-diagnostic kits and UNICO 7200 spectrophotometer according to the manufacturer's protocol. All collected samples were placed on crushed ice and were taken immediately after collection to microbiology and immunology 
laboratory, Faculty of medicine, Zagazig University to be stored frozen at $\quad-20$ degrees until used for biochemical measurements.

\section{Statistical analysis}

All data were collected, tabulated and statistically analyzed using SPSS 20.0 for windows (SPSS Inc., Chicago, IL, USA), MedCalc 13 for windows (MedCalc Software bvba, Ostend, Belgium) and Microsoft Office Excel 2010 for windows (Microsoft Cor., Redmond, WA, USA). Quantitative data were expressed as the mean \pm SD $\&$ median (range). Continuous data were checked for normality by using Shapiro Walk test. Mann Whitney U test was used to compare two groups of non-normally distributed data. Kraskall Wallis $\mathrm{H}$ was used to compare more than two groups of non-normally distributed data. Post-hoc test was done by Tamhane's T2 test. Receiver operating characteristic (ROC) curve analysis was used to identify optimal cut-off values of salivary total proteins and amylase with maximum sensitivity and specificity for diagnosis leukemia. Area under Curve (AUROC) was also calculated, criteria to qualify for AUC were as follows: $0.90-1=$ excellent, 0.80$0.90=$ good, $0.70-0.80=$ fair; $0.60-0.70=$ poor; and $0.50-0.6=$ fail. The optimal cutoff point was established at point of maximum accuracy. All tests were two sided. $\mathrm{p}<0.05$ was considered statistically significant.

\section{RESULTS}

Kraskall Wallis $\mathrm{H}$ results showed that, there were significant differences in means of salivary flow rate, $\mathrm{pH}$, total proteins and alpha amylase between group A (healthy children), group B (leukemic children before chemotherapy) and group $\mathrm{C}$ (leukemic children after chemotherapy) as shown in table (1)

\section{Salivary flow rate}

Further analysis using a Post-hoc test showed a significant difference in the mean of salivary flow rate values between healthy children (group A) and leukemic children after chemotherapy (group C), also the difference was significant between the leukemic children before (group B) and after chemotherapy (group C). On the other hand, there was no significant difference between the healthy children (group A) and the leukemic children before chemotherapy (group B).

\section{pH}

Regarding mean $\mathrm{pH}$ value, there was a significant difference between group $A$ and the other two groups $\mathrm{B} \& \mathrm{C}$, also results showed a significant difference in mean $\mathrm{pH}$ values between group $\mathrm{B}$ and group $\mathrm{C}$.

\section{Salivary total proteins and alpha amylase}

The findings showed that the means of salivary total proteins and salivary alpha amylase were significantly higher in group B than in group A and group C. But there was no significant difference in means of salivary total proteins and salivary amylase between group A and group $\mathrm{C}$.

Results of ROC curve analysis showed that the total salivary proteins concentration in saliva is the best indicator to predict leukemia before starting any treatment with chemotherapy with high specificity and sensitivity, where values above $8.381 \mathrm{~g} / \mathrm{dl}$ indicated leukemia with accuracy $100 \%$. Salivary amylase is of significant interest in predicting leukemia with values above 465.618 $\mathrm{u} / \mathrm{l}$ are considered the best cut-off point where maximum sensitivity $96.7 \%$ and specificity $93.3 \%$ and accuracy of $95 \%$. In contrast to that, the $\mathrm{pH}$ test is considered as poor indicator as its accuracy is 0.70. (Table 2 \& Figure 1) 
TABLE (1): Comparison between healthy and leukemic children (before and after chemotherapy).

\begin{tabular}{|c|c|c|c|c|}
\hline Variables & $\begin{array}{l}\text { Salivary flow } \\
(\mathrm{ml} / \mathrm{min})\end{array}$ & pH & $\begin{array}{l}\text { Total protein } \\
\qquad(\mathrm{g} / \mathrm{dl})\end{array}$ & $\begin{array}{l}\text { Amylase } \\
\qquad(\mathbf{u} / \mathbf{l})\end{array}$ \\
\hline Group A (N=15) & $\begin{array}{c}0.91 \pm 0.30 \\
0.80(0.50-1.70)\end{array}$ & $\begin{array}{c}7.77 \pm 0.25 \\
7.70(7.50-8.50)\end{array}$ & $\begin{array}{c}7.535 \pm 0.493 \\
7.556(6.691-8.382)\end{array}$ & $\begin{array}{c}329.59 \pm 105.44 \\
340.898(124.72-515.51)\end{array}$ \\
\hline Group B (N=15) & $\begin{array}{c}1.01 \pm 0.38 \\
1(0.50-2.00)\end{array}$ & $\begin{array}{l}7.47 \pm 0.48 \\
7.50(6-8) \\
\end{array}$ & $\begin{array}{c}11.247 \pm 0.566 \\
11.339(10.188-12.374)\end{array}$ & $\begin{array}{c}534.21 \pm 38.68 \\
537.260(456.16-618.36)\end{array}$ \\
\hline Group C $(\mathrm{N}=15)$ & $\begin{array}{c}0.35 \pm 0.15 \\
0.30(0.20-0.80)\end{array}$ & $\begin{array}{l}6.74 \pm 0.81 \\
6.90(5-8)\end{array}$ & $\begin{array}{c}7.883 \pm 1.084 \\
7.506(6.800-1.244)\end{array}$ & $\begin{array}{c}282.30 \pm 46.17 \\
263.56(233.15-425.70)\end{array}$ \\
\hline p-value & $<0.001 \bullet$ & $<0.001 \bullet$ & $<0.001 \bullet$ & $<0.001 \bullet$ \\
\hline $\begin{array}{c}\text { Group A } \\
\text { vs } \\
\text { Group B }\end{array}$ & $0.580, \mathrm{NS}$ & $0.014, \mathrm{~S}$ & $<0.001, \mathrm{~S}$ & $<0.001, \mathrm{~S}$ \\
\hline $\begin{array}{c}\text { Group A } \\
\text { vs } \\
\text { Group C }\end{array}$ & $<0.001, \mathrm{~S}$ & $<0.001, \mathrm{~S}$ & $0.313, \mathrm{NS}$ & $0.087, \mathrm{NS}$ \\
\hline $\begin{array}{l}\text { Group B } \\
\text { vs } \\
\text { Group C }\end{array}$ & $<0.001, \mathrm{~S}$ & $<0.001, \mathrm{~S}$ & $<0.001, \mathrm{~S}$ & $<0.001, \mathrm{~S}$ \\
\hline
\end{tabular}

-Kraskall Wallis H test; + Chi-square test; Post-hoc test, Tamhane’s T2 test. $p<0.05$ is significant (s), p>0.05 not significant (NS) .

TABLE (2): Salivary total protein, amylase and $\mathrm{pH}$ as diagnostic markers for leukemia.

\begin{tabular}{|c|c|c|c|}
\hline Parameter & Total Proteins & Amylase & pH \\
\hline Cut off & $>8.381 \mathrm{~g} / \mathrm{dl}$ & $>465.618 \mathrm{u} / \mathrm{l}$ & \multicolumn{1}{c|}{$100 \%$} \\
\hline Sensitivity & $100 \%$ & $96.7 \%$ & $100 \%$ \\
\hline Specificity & $100 \%$ & $93.3 \%$ & $62.5 \%$ \\
\hline Positive predictive value & $100 \%$ & $93.5 \%$ & $70 \%$ \\
\hline
\end{tabular}

ROC curve: Receiver Operating Characteristic curve 


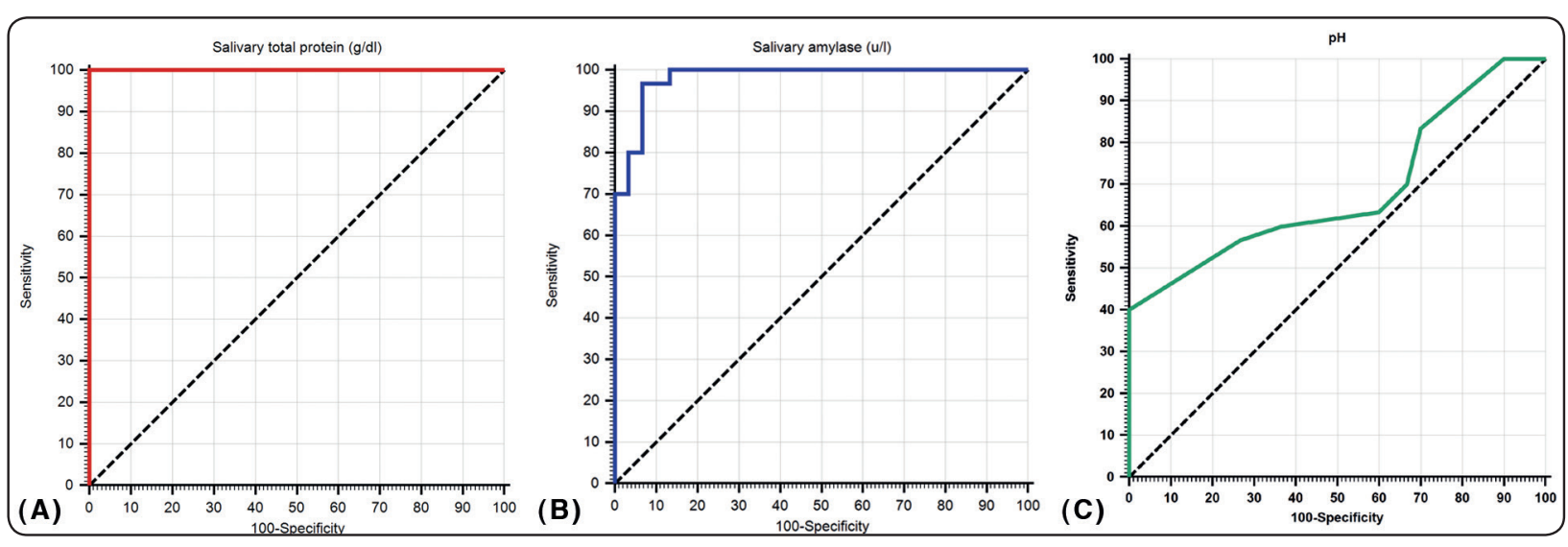

Fig. (1): Receiver operating characteristic (ROC) curve of salivary total protein (A), salivary amylase (B), and pH (C) as diagnostic markers for leukemia.

\section{DISCUSSION}

Saliva is an informative body fluid, which is easy to collect; transport and store, no special equipment or skilled person is needed for its collection. Because of its accessibility and correlation to multiple systemic diseases, salivary components can be considered as a mirror of the body's health ${ }^{11,12}$. Perhaps, no other patient population could benefit more from these advances than pediatrics to reduce trauma and limit anemia $^{13,14}$. It is essential for the professional dentist to be able to recognize the normal oral and salivary physiological characteristics and when identifying any change from normal range to fully investigate it by requesting additional tests or referring the patient to specialized professionals ${ }^{15}$. The current study aimed to investigate the effect of acute lymphoblastic leukemia on salivary alterations in leukemic children before and after chemotherapy induction.

In this study, there was a significant reduction of salivary flow rate mean values in group $\mathrm{C}$ (children after chemotherapy induction) compared to group A (healthy children) and group B (leukemic children before chemotherapy induction). Parallel results were seen in previous studies ${ }^{16,17}$, as they found that chemo-radiotherapy causes a decrease in salivary flow rate in leukemic patients, which can be attributed to hypo-function and hypoplasia of the salivary glands in patients receiving chemoradiotherapy. These results are also in agreement with those of Emidio et al 2010 and Mathur et al $2012^{4,18}$. They explained their findings on the basis of tertiary complications in leukemic children, the tertiary complications are usually due to a complex interplay of the therapy itself, its side effect, and a systemic condition arising out of the therapy. In group $\mathrm{B}$, there is a significant decrease $\mathrm{pH}$ mean value compared to group A. A possible explanation for this finding may be due to the infiltration of malignant cells into the oral structures, gingiva, bone, and salivary glands as a primary complication of leukemia. In addition, there is a significant reduction in $\mathrm{pH}$ mean values of group $\mathrm{C}$ in relation to groups A and B. This result was supported by many studies ${ }^{4,17,18}$, since the induction of chemotherapeutic agents causes fibrosis, degeneration of salivary acinar cells and necrosis of salivary glands that lead to this reduction in salivary $\mathrm{pH}$. In relation to the level of total salivary proteins and alpha amylase, the outcome of the present study showed that the means of salivary total proteins and salivary alpha amylase were significantly higher in group B than in group A and Group C, these results are agreed with many previous studies ${ }^{19-23}$. These findings were 
supported by the ROC analysis, which showed that the salivary total proteins test is considered as an excellent predictor test for the presence of leukemia as its accuracy equals to $100 \%$, while alpha amylase test is classified as a good test but the $\mathrm{pH}$ test is considered as poor one. Salivary proteins are mainly responsible for innate immunity via their immune activator and/or immune modulator properties 24,25 therefore, their levels undergo considerable variations in different pathological conditions and different types of cancers ${ }^{26-29}$.

\section{CONCLUSION:}

The present study may provide proof-ofprinciple that saliva, when used as a diagnostic tool, can help dentists in making a proper decision in the diagnosis of leukemia. Salivary total proteins reflect an excellent predictor test for ALL leukemia in children.

\section{ACKNOWLEDGMENTS}

The authors wish to thank Prof.Dr.UsamaAl Safy, Head of Pediatrics and Haematoloy Department, Faculty of Medicine, Zagazig University and Prof. Dr. Hosam Elsharkawy, Prof. of Microbiology and Immunology, Faculty of Medicine, Zagazig University for laboratory work and data collection.

\section{REFERENCES:}

1. Cho SY, Cheng AC, Cheng MC. Oral care for children with leukaemia. Hong Kong Med J 2000;6:203-208.

2. Arora RS, Eden TO, Kapoor G. Epidemiology of childhood cancer in India. Indian J Cancer 2009;46:264-273.

3. Hoda V, Nasim M, Moeini M, Baser R, Masoomi Y, Moeini M. The dentists role in improving the life's quality of children with leukemia. Am J Res Commun 2013;1:66-77.

4. Mathur VP, Dhillon JK, Kalra G. Oral health in children with leukemia. Indian J Palliat Care 2012;18(1): 12-18.

5. Shankar AA, Routray S. Trends in salivary diagnostics - a 5-year review of oral oncology. Oral Oncol 2012; 48: e22-23
6. Wu JY, Yi C, Chung HR, Wang DJ, Chang WC, et al. Potential biomarkers in saliva for oral squamous cell carcinoma. Oral Oncol 2010;46: 226-223.

7. Afrooz Nakhostin, and Ghasem Meighani. Leukemia and its Oral Manifestations in Children Younger than 12 Years Referred to Tehran Pediatric Hospitals. Avicenna J Dent Res. In Press: doi: 10.17795/ajdr -e29995.Published online 2016 July 17.

8. Navazesh M. Methods for collecting saliva. Ann NY Acad Sci 1993; 20:72-77.

9. Gornall, A.G., Bardawil, C.J. and David, M.M Determination of serum proteins by means of the Biuret reaction. J. Biol. Chem.1949; 177:751- 766.

10. Caraway WT. A stable starch substrate for the determination of amylase in serum and other body fluids. American Journal of Clinical Pathology 1959; 32:97-99.

11. Schafer CA, Schafer JJ, Yakob M, Lima P, Camargo P, Wong DT. Saliva diagnostics: utilizing oral fluids to determine health status. Monogr Oral Sci (2014) 24:8898. doi:10.1159/000358791

12. Javaid MA, Ahmed AS, Durand R, Tran SD. Saliva as a diagnostic tool for oral and systemic diseases. J Oral Biol Craniofac Res (2016) 6:66-75. doi:10.1016/j. jobcr. 2015.08.006

13. Ranger M, Grunau RE. Early repetitive pain in preterm infants in relation to the developing brain. Pain Manag 2014; 4:57-67. doi:10.2217/pmt.13.61 13 .

14. Vinall J, Grunau RE. Impact of repeated procedural painrelated stress in infants born very preterm. Pediatr Res 2014;75:584-7. doi:10.1038/ pr.2014.16 14

15. Joshi SR, Pendyala GS, Kasat VO, Mopagar V, Chaudhari S. Oral and dental management of leukemic children. Indian J Oral Sci 2016;7:70-73.

16. Barbosa AM, Ribeiro DM, Coldo-Teixeira AS Conhecimentos epráticas em saúde bucal com crianças hospitalizadas com câncer. Ciência \& Saúde Coletiva 2010; 15(1):1113-1122 .

17. Hollingsworth B, Senter L, Zhang X, Brock GN, Jarjour W, Nagy R. et al. Risk factors of 131i-induced salivary gland damage in thyroid cancer patients. J Clin Endocrinol Metab 2016; 101(11):4085-4093.

18. Emidio TC, Maeda YC, Caldo-Teixeira AS, Puppin-Rontani RM. Oral manifestations of leukemia and antineoplastic 
treatment - A literature review (part II). Braz J Health 2010;1:136-149.

19. Rahemtulla M, Techanitiswad T, Rahemtulla F, McMillan T, Bradley E, Wahlin Y. Analysis of salivary components in leukemia patients receiving chemotherapy. Oral surgery, Oral Medicine, Oral Pathology 1992;73:35-46.

20. Ashok L, Sujatha GP, Hema G. Estimation of salivary amylase and total proteins in leukemia patients and its correlation with clinical feature and radiographic finding. Indian journal of dental research 2010; 21: 486-490.

21. Rahul R Deshpande, Megha V Jadhav, Vishwas Patil, Rajdeep Singh, Mayuri Mutha, Bhavana S. Comparative evaluation of total salivary proteins in leukemic and healthy children of mixed dentition age group. Research Journal of Pharmaceutical, Biological and Chemical Sciences 2014; 5(1):126-131.

22. Shalaby R.A, Elbaz G.A, Aboelmaatty D.M, AbdAlkhalek W M. Evaluation of some salivary parameters in leukemic children. Egyptian Dental Journal 2016; 62(4) :3997-4002.

23. Ghalaut Pankaj., Bala Jyoti., Singh Ragini., Ghalaut Veena Singh and Saurabh Kumar. Salivary amylase and total protein levels in leukemias. International journal of current advanced research 2016;(5) 8, 1199-1202.
24. Karolewska E, Konoka T, Pupek M, Chaber R. Mucositis in children with leukemia and salivary defense factors. Dent Med Probl 2007;44:30-36.

25. Fabian TK, Hermann P, Beck A, Fabian G. Salivary defense proteins: their network and role in innate and acquired oral immunity. Int J MolSci 2012;13: 4295-4320.

26. Guerra R.N., Oliveira-Junior J.J., Mouchrek-Filho J.C., Liberio S.A., Lima M.V., Paim D.B. et al. Salivary evaluation of pediatric patients with cancer, before and after antineoplasic treatment. J. Oral Pathol. Med. 2012; 41:527-532.

27. Xie Z., Chen G., Zhang X., Li D., Huang J., Yang C. et al. Salivary microRNAs as promising biomarkers for detection of esophageal cancer. PLoS ONE. 2013;8:1531 doi: 10.1371/journal.pone.0057502.

28. Xie Z., Yin X., Gong B., Nie W., Wu B., Zhang X. et al. Salivary microRNAs show potential as a noninvasive biomarker for detecting resectable pancreatic cancer. Cancer Prev. Res. 2015;8:165-173. doi: 10.1158/19406207.CAPR-14-0192.

29. Katsiougiannis $S$ and Wong DT. The proteomics of saliva in Sjgren's syndrome. Rheum Dis Clin North Am 2016;42:449-456. 